\title{
Desempenho de ovinos terminados em confinamento com resíduo desidratado de vitivinícolas associado a diferentes fontes energéticas
}

\author{
Performance of sheep in feedlot termination fed with dried grapes residue diets associated with \\ different energy sources
}

\author{
Daerson Dantas Barroso ${ }^{1}$ Gherman Garcia Leal de Araújo ${ }^{2}$ Divan Soares da Silva ${ }^{3}$ \\ Severino Gonzaga Neto ${ }^{3}$ Fernando Thomaz Medina ${ }^{4}$
}

\section{RESUMO}

Foram avaliados os efeitos de dietas combinando o resíduo de vitivinícolas a diferentes fontes energéticas sobre consumo, ganho de peso diário e conversão alimentar em ovinos terminados em confinamento. Foram utilizados 18 ovinos sem padrão racial definido, não castrados, com idade aproximada de sete meses e peso vivo médio inicial de $23,0 \mathrm{~kg}$, distribuídos num delineamento em blocos casualizados, com três tratamentos e seis repetições. O período experimental constou de 63 dias, sendo as dietas compostas de $50 \%$ de resíduo de vitivinícolas e 50\% de concentrados energéticos: grão de milho moído (Zea mays) (T1), raspa de mandioca (Manihot esculenta) enriquecida com 1,8\% de uréia (T2) $e$ farelo de palma forrageira (Opuntia ficus) enriquecido com 1,1\% de uréia (T3). Foram avaliados os consumos de matéria seca (MS), proteína bruta (PB) e carboidratos totais (CHOT), ganho de peso diário e total e a conversão alimentar. Os consumos de MS, PB e CHOT foram de 1.085, 906 e $1.508 \mathrm{~g}$ dia $^{-1}$; 129, 139 e 220g dia ${ }^{-1} ; 846,691$ e 1.157g dia ${ }^{-1}$; os ganhos de peso médio diário foram de 117, 71 e 132g; a conversão alimentar de 9,50;13,28 e 11,30, respectivamente para as combinações de resíduo e grão de milho moído, raspa de mandioca e farelo de palma. As médias diárias de ganho de peso vivo obtidas pelos ovinos ao longo do período de engorda revelaram um bom potencial forrageiro do resíduo de vitivinícolas combinado às diferentes fontes energéticas.

Palavras-chave: consumo, conversão alimentar, ganho de peso.

\section{ABSTRACT}

The effect of combining diets residues from grapewine industries with different energy sources on consumption, daily weight gain and feed conversion of sheep in feedlot termination were evaluated. Eighteen seven-month old male sheep, non-defined breed, were used, weighted initialy $23.0 \mathrm{~kg}$, distributed in randomized blocks with three treatments and six repetitions. The experimental period consisted of 63 days, being the diets composed of $50 \%$ of grapewine industry residue and 50\% of energy concentrate: ground corn grain (Zea mays) (T1), cassava chips (Manihot esculenta) enriched with $1.8 \%$ of urea (T2) and fodder cactus dried meal (Opuntia ficus) enriched with $1.1 \%$ of urea (T3). Intakes of dry matter (DM), crude protein (CP) and total carbohydrate (TCHO) were evaluated, as well as daily and total weight gains and feed conversion. Respectively for the combination of residue and ground corn grain, for cassava chips and for fodder cactus dried meal, intakes of MS, PB and CHOT were 1085, 906 and $1508 \mathrm{~g} \mathrm{dia}^{-1} ; 129,139$ and $220 \mathrm{~g} \mathrm{dia}^{-1} ; 846,691$ and $1157 \mathrm{~g}$ day $^{-1}$; average daily weight gains were $117 \mathrm{~g}, 71 \mathrm{~g}$ and $132 \mathrm{~g}$; feed conversions were 9.50, 13.28 and 11.30. Daily averages of live weight gains obtained by sheep during the fattening period showed a good forage potential of the residues of grapewine industries combined with different energetic sources.

Key words: intake, feed conversion, weight gain.

\section{INTRODUÇÃO}

Os resíduos agroindustriais, segundo OLIVEIRA (2003), representam um recurso alimentar passível de aproveitamento na alimentação dos ruminantes. $\mathrm{O}$ mesmo autor alerta também que a exploração desses resíduos na alimentação animal ainda é pequena e empírica, gerando poluição ambiental em função do montante produzido.

Na região do Vale do São Francisco, o resíduo de vitivinícolas está sendo em grande parte

\footnotetext{
${ }^{1}$ Centro Federal de Educação Tecnológica de Petrolina, PE, Brasil. E-mail: daersonbarroso@yahoo.com.br.

${ }^{2}$ Embrapa Semi-Árido, Br 428, Km 152, Zona Rural, CP 23, 56300-000, Petrolina, PE, Brasil.

${ }^{3}$ Departamento de Zootecnia, Centro de Ciências Agrárias, Campus II, Universidade Federal da Paraíba (UFPB), 56397-000, Areia, PB, Brasil.

${ }^{4}$ Centro Federal de Educação Tecnológica de Petrolina, PE, Brasil.
} 
desperdiçado, podendo, ser aproveitado na alimentação animal sob as formas de silagem ou resíduo desidratado, garantindo um bom aporte de nutrientes para os animais, principalmente no período de maior escassez de forragem. Pode-se ainda beneficiar a produção familiar do caprino-ovinocultor, garantindo o aumento de sua renda pelo aumento da produtividade.

A terminação de ovinos exclusivamente a pasto, praticada na maioria das propriedades rurais do semi-árido nordestino, tem-se mostrado ineficaz em grande parte dos sistemas de produção, pois este processo está submetido à irregularidade na disponibilidade de forragem da caatinga, ocasionando longos períodos para os animais alcançarem o peso de abate. Por outro lado, há uma grande demanda de carne ovina, o que requer, práticas voltadas para o aumento da produtividade da espécie e para a oferta de seus produtos. BARROS et al. (1997) relataram que cordeiros "Morada Nova" mantidos em pastagem nativa perderam peso no montante de $10 \mathrm{~g}$ animal ${ }^{-1} \mathrm{dia}^{-1}$ no período seco.

O confinamento de ovinos para abate tem recebido nos últimos anos uma crescente adoção em virtude dos benefícios que traz esta prática, principalmente pela redução do tempo para o abate, pela maior eficiência no controle sanitário, pela melhor qualidade das carcaças e peles e pela manutenção da oferta no período de escassez de forragens, buscando atender a constante demanda nesse período, como também pelo melhor preço pago pelo produto. BARROS et al. (1997) relataram que cordeiros "Morada Nova" que receberam o tratamento do semiconfinamento apresentaram $42 \mathrm{~g}$ animal ${ }^{-1} \mathrm{dia}^{-1}$ de ganho de peso. Por outro lado, nos animais confinados, o ganho variou de 44 a $267 \mathrm{~g}$ animal ${ }^{-1} \mathrm{dia}^{-1}$, permitindo concluir que a terminação de cordeiros em confinamento no Nordeste do Brasil pode ser utilizada para aumentar a oferta de carne e pele. O consumidor tem preferência por carcaças de tamanho moderado, entre $12-14 \mathrm{~kg}$, o que determina o abate dos animais com 28-30kg de peso vivo (SIQUEIRA, 1999).

Com a realização deste trabalho, objetivouse avaliar o efeito da combinação do resíduo desidratado de vitivinícolas a diferentes fontes energéticas em dietas para ovinos terminados em confinamento sobre o seu consumo, o seu ganho de peso e a sua conversão alimentar.

\section{MATERIAL E MÉTODOS}

O experimento foi realizado no período de junho a agosto de 2004, no Setor de Nutrição Animal da Embrapa Semi-Árido, em Petrolina-PE, situado às margens da $\mathrm{Br}$ 428, km 152 da rodovia Petrolina - Lagoa Grande-PE, a uma latitude de $09^{\circ} 09^{\prime}$, S, longitude de $40^{\circ} 22^{\prime \prime} \mathrm{W}$, altitude de $365,5 \mathrm{~m}$ e média pluviométrica anual de 570mm, com temperaturas médias anuais e máximas e mínimas de 32,46 e $20,87^{\circ} \mathrm{C}$, respectivamente.

Foram utilizados 18 ovinos sem padrão racial definido, não castrados, com idade aproximada de sete meses e $23 \mathrm{~kg}$ de peso vivo médio inicial, oriundos de sistemas extensivos de produção em caatinga e distribuídos num delineamento experimental em blocos casualizados, com três tratamentos e seis repetições, considerando o peso como fator de controle.

Previamente ao início do experimento, os animais foram identificados com brincos numerados, vermifugados, pesados, sorteados em seus tratamentos e mantidos em baias individuais contendo água, alimento e mistura mineral à vontade, sendo as baias submetidas a limpezas periódicas.

Foram avaliadas três dietas, formuladas com base nas exigências nutricionais para ovinos em engorda com $30 \mathrm{~kg}$ de peso vivo e ganho de peso diário esperado de 200g, (NRC, 1975) para consumo de 4,3\% do peso vivo de MS e teores de $11,0 \%$ de PB e $64 \%$ de NDT na MS total da dieta.

As dietas foram compostas de resíduo desidratado de vitivinícolas como volumoso, combinado aos seguintes concentrados energéticos: grão de milho moído (Zea mays) (T1), raspa de mandioca (Manihot esculenta) enriquecida com 1,8\% de uréia (T2) e farelo de palma forrageira (Opuntia ficus) enriquecido com 1,1\% de uréia (T3), com uma relação volumoso:concentrado 50:50. O enriquecimento das dietas com uréia foi feito com o objetivo de torná-las isoprotéicas.

O resíduo foi doado pela Vitivinícola Santa Maria LTDA, resultante do processamento das uvas para a produção de vinho, sendo basicamente composto de casca, semente e polpa. O grão de milho, a raspa de mandioca e o farelo de palma foram produzidos no Setor de Nutrição Animal da Embrapa Semi-Árido, resultantes da secagem e trituração de seus respectivos materiais de origem.

As dietas foram fornecidas à vontade duas vezes ao dia, às 8 e 15 horas, durante todo o período experimental, ajustando-se uma sobra diária de aproximadamente $20 \%$ do oferecido por animal. A composição químico-bromatológica dos ingredientes e das dietas é mostrada nas tabelas 1 e 2 , respectivamente.

Para determinação do consumo de MS, PB e CHOT, foram feitas pesagens diárias do oferecido e das sobras, como também coletas de amostras semanais, as quais tiveram a matéria seca e a proteína bruta determinadas segundo metodologia descrita por 
Tabela 1 - Teores médios de matéria seca (MS), matéria orgânica (MO), matéria mineral (MM), proteína bruta (PB), fibra em detergente neutro (FDN), fibra em detergente ácido (FDA), extrato etéreo (EE), carboidratos totais (CHOT), lignina (LN) e digestibilidade “in vitro” da MS (DIVMS) dos ingredientes utilizados na formulação das dietas, expressos na matéria seca.

\begin{tabular}{|c|c|c|c|c|}
\hline Parâmetros (\%) & Resíduo de vitivinícolas & Grão de milho moído & Raspa de mandioca & Farelo de palma \\
\hline MS & 90,60 & 89,20 & 89,43 & 89,00 \\
\hline MO & 87,72 & 97,04 & 95,64 & 81,05 \\
\hline MM & 12,28 & 2,95 & 4,36 & 18,05 \\
\hline $\mathrm{PB}$ & 17,00 & 8,46 & $8,19 *$ & $8,50 * *$ \\
\hline FDN & 60,36 & 15,46 & 16,42 & 40,90 \\
\hline FDA & 52,19 & 5,18 & 10,89 & 31,87 \\
\hline $\mathrm{EE}$ & 5,15 & 6,66 & 0,58 & 0,70 \\
\hline CHOT & 65,57 & 81,93 & 86,87 & 76,25 \\
\hline $\mathrm{LN}$ & 22,00 & 0,61 & 2,05 & 3,88 \\
\hline DIVMS & 30,00 & 76,53 & 62,83 & 60,72 \\
\hline
\end{tabular}

*raspa de mandioca $+1,8 \%$ de uréia $\quad * *$ farelo de palma $+1,1 \%$ de uréia.

SILVA \& QUEIROZ (2002). Os carboidratos totais foram obtidos pela fórmula $100-(\mathrm{MM}+\mathrm{PB}+\mathrm{EE})$. Os nutrientes digestíveis totais foram obtidos pela relação entre a ingestão total de MS e a de NDT. Para o ganho de peso vivo diário considerado num período de 63 dias, foram feitas pesagens no início do experimento e a cada sete dias, sem jejum prévio. A conversão alimentar foi obtida pela relação entre o consumo de MS e o ganho de peso total no período experimental.

As variáveis estudadas foram interpretadas por análise de variância e teste de Duncan, utilizandose o SAS (2004) com níveis de 5\% de probabilidade.

\section{RESULTADOS E DISCUSSÃO}

Observa-se que o tipo de concentrado energético associado ao resíduo de vitivinícolas influenciou $(\mathrm{P}<0,05)$ o ganho de peso diário dos animais aos 63 dias, com maiores respostas em ganho de peso para os animais alimentados com as dietas compostas por resíduo e grão de milho moído e resíduo e farelo de palma, que não diferiram $(\mathrm{P}>0,05)$ entre si (Tabela 3$)$. A rentabilidade é o principal ponto de interesse em um sistema de terminação em confinamento. BARROS et al. (1997) comentam que maior rentabilidade é conseguida com menor tempo de confinamento. No presente trabalho, maior rentabilidade pode estar ligada a menores custos de produção para o farelo de palma em relação às demais fontes energéticas, considerando o bom comportamento produtivo e adaptativo desta cultura às condições climáticas da região semi-árida e a facilidade de acesso e cultivo por parte dos produtores.

Provavelmente, o maior consumo de MS, PB e CHOT obtido para a combinação de resíduo e farelo de palma em relação às demais e o maior consumo

Tabela 2 - Composição percentual das dietas e os respectivos teores de matéria seca (MS), matéria orgânica (MO), matéria mineral (MM), proteína bruta (PB), fibra em detergente neutro (FDN), fibra em detergente ácido (FDA), extrato etéreo (EE), lignina (LN), carboidratos totais (CHOT) e NDT expressos na matéria seca.

\begin{tabular}{lccc}
\hline Parâmetros & $\begin{array}{c}50 \% \text { de resíduo }+50 \% \text { de grão de } \\
\text { milho moído }\end{array}$ & $\begin{array}{c}50 \% \text { de resíduo }+50 \% \text { de raspa de } \\
\text { mandioca }\end{array}$ & $\begin{array}{c}50 \% \text { de resíduo }+50 \% \text { de farelo de } \\
\text { palma }\end{array}$ \\
\hline MS & 89,90 & 90,01 & 89,80 \\
MO & 92,38 & 91,68 & 84,38 \\
MM & 7,61 & 8,32 & 15,16 \\
PB & 12,73 & 12,59 & 12,75 \\
FDN & 37,91 & 38,39 & 50,63 \\
FDA & 28,68 & 31,54 & 42,03 \\
EE & 5,90 & 2,86 & 2,92 \\
LN & 11,30 & 12,02 & 12,94 \\
CHOT & 73,75 & 76,22 & 70,91 \\
NDT & 45,73 & 43,31 & 40,00 \\
\hline
\end{tabular}

Ciência Rural, v.36, n.5, set-out, 2006. 
Tabela 3 - Médias e coeficiente de variação (CV), do ganho diário de peso vivo (GPVD), expresso em gramas por dia (g/dia-1 ${ }^{-1}$, do consumo de matéria seca total (CMST) e em gramas por dia (CMS), do consumo de proteína bruta (CPB), do consumo de carboidratos totais (CCHOT) e da conversão alimentar da matéria seca (CAMS), além dos pesos vivo inicial (PVI), final (PVF) e ganho de peso vivo total (GPVT) para cordeiros no período de 63 dias de confinamento.

\begin{tabular}{|c|c|c|c|c|}
\hline Parâmetros & $\begin{array}{l}50 \% \text { de resíduo + 50\% de grão de } \\
\text { milho moído }\end{array}$ & $\begin{array}{l}50 \% \text { de resíduo }+50 \% \text { de raspa } \\
\text { de mandioca }\end{array}$ & $\begin{array}{l}50 \% \text { de resíduo }+50 \% \text { de farelo } \\
\text { de palma }\end{array}$ & CV (\%) \\
\hline PVI (kg) & 23,7 & 21,4 & 24,1 & - \\
\hline PVF (kg) & 31,0 & 25,8 & 32,5 & - \\
\hline GPVD (g/dia $\left.{ }^{-1}\right)$ & $117 \mathrm{a}$ & $71 \mathrm{~b}$ & $132 \mathrm{a}$ & 26,53 \\
\hline GPVT(kg) & $7,37 \mathrm{a}$ & $4,47 \mathrm{~b}$ & 8,40 a & 22,18 \\
\hline CMST(kg) & $68,4 \mathrm{~b}$ & $57,10 \mathrm{c}$ & 95,0 a & 27,13 \\
\hline CMS (g/dia $\left.{ }^{-1}\right)$ & 1085 b & $906 \mathrm{c}$ & 1508 a & 25,31 \\
\hline CPB $\left(\mathrm{g} / \mathrm{dia}^{-1}\right)$ & $129 \mathrm{~b}$ & $139 \mathrm{~b}$ & $220 \mathrm{a}$ & 19,84 \\
\hline CCHOT (g/dia $\left.{ }^{-1}\right)$ & $846 \mathrm{~b}$ & $691 \mathrm{c}$ & 1157 a & 21,20 \\
\hline CAMS & $9,28 \mathrm{a}$ & $12,77 \mathrm{c}$ & $11,30 \mathrm{~b}$ & 13,01 \\
\hline
\end{tabular}

Médias seguidas de letras diferentes na mesma linha diferem estatisticamente a 5\% de significância pelo teste de Duncan.

de MS e CHOT observado para a combinação de resíduo e grão de milho moído em relação à raspa de mandioca (Tabela 3) proporcionaram melhor desempenho dos animais em função de uma maior disponibilidade de nutrientes para o metabolismo, tomando por base que, segundo MERTENS (1994), 60 a $90 \%$ das diferenças no desempenho animal é função do consumo e 10 a $40 \%$ é função da digestibilidade. MENDES NETO et al. (1998) comentaram que normalmente, nos confinamentos, os maiores ganhos de peso são obtidos em função de um maior consumo. A igualdade de ganho de peso verificada entre as dietas com farelo de palma e grão de milho moído, mesmo com as diferenças em consumo, pode ser explicada pela digestibilidade dos ingredientes, visto que o grão de milho moído apresentou maiores valores de DIVMS (Tabela 1) e maiores valores de NDT quando combinado ao resíduo de vitivinícolas (Tabela 2).

Os menores consumos de MS e CHOT obtidos para a combinação de resíduo e raspa de mandioca (Tabela 3) indicam menor aporte de energia para esta combinação, justificando o menor desempenho. A energia tem sido destacada pelos especialistas como sendo o componente nutricional de mais difícil atendimento e que mais afeta negativamente o desempenho dos ruminantes em sistemas de produção a base de recursos forrageiros e resíduos agroindustriais disponíveis no semi-árido nordestino.

Os resultados médios de ganho de peso diário obtidos neste trabalho para as três combinações avaliadas (106 g) são superiores aos obtidos por PILAR et al. (1998), que obtiveram 49g, alimentando ovinos com silagem de milho + bagaço de mandioca. São valores superiores ainda aos obtidos por ARAÚJO et al. (2001), que, alimentando ovinos com níveis crescentes de feno de maniçoba, obtiveram ganhos de $44 \mathrm{~g}$, sendo, por fim, superiores aos de CARVALHO et al. (1995), com ganhos médios de 66g para níveis crescentes de casca de café na alimentação de ovinos. Estes valores de ganhos, no entanto, são inferiores aos produzidos com alimentos alternativos citados por PEREZ \& GARCIA (1998), de 216g dia ${ }^{-1}$, submetendo ovinos "Santa Inês" a níveis crescentes de dejetos de suínos, e por CUNHA et al. (2004), reportando ganhos de 231 e 173g com ovinos "Santa Inês", respectivamente, para resíduo de abacaxi fenado + feno de maniçoba e resíduo de abacaxi ensilado + fenos de capim-elefante e de maniçoba.

As dietas foram formuladas buscando alcançar um ganho diário de $200 \mathrm{~g} \mathrm{dia}^{-1}$, segundo o NRC (1975); no entanto, em nenhuma das dietas testadas o referido ganho foi alcançado. Esse comportamento pode estar relacionado ao baixo potencial genético dos animais e a possíveis limitações nutricionais, sobretudo de energia, em função dos altos teores de fibra em detergente neutro e de lignina do resíduo (Tabela 1), indicativos de baixa digestibilidade e baixa disponibilidade energética. Todavia, vale ressaltar que os ganhos de peso obtidos neste estudo para o tipo de animal e ingredientes utilizados na formulação das dietas são considerados satisfatórios, uma vez que a maioria dos concentrados energéticos utilizados são oriundos de culturas com boas respostas produtivas e adaptativas à região semi-árida, como a palma e a mandioca.

Destaca-se ainda o bom desempenho do volumoso, por tratar-se de um subproduto da indústria 
do vinho, que até então vinha tendo um aproveitamento parcial, o que garante, com esta iniciativa, além da possibilidade de uso de um recurso volumoso alternativo, a retirada do ambiente de um material que, pelo volume atualmente gerado e pelas perspectivas futuras, poderá se tornar em um montante danoso ao ambiente.

A conversão alimentar da MS sofreu efeito $(\mathrm{P}<0,05)$ da fonte energética da dieta (Tabela 3), com maior eficiência para a combinação do resíduo com o grão de milho moído, seguido pelo farelo de palma e raspa de mandioca. Diversos resultados têm indicado diferenças na taxa de conversão alimentar, a partir de diferenças no teor energético da ração (EUCLIDES FILHO et al., 1996). Segundo NEUMANN (1977), maior densidade energética resulta em maior ingestão de energia, por conseguinte, menos alimento é requerido para o ganho de peso, o que pode ter ocorrido no presente trabalho, no qual os melhores resultados de conversão foram obtidos para as dietas com grão de milho moído e farelo de palma, as quais apresentaram as maiores ingestões de CHOT (Tabela 3). A maior eficiência de conversão alimentar do grão de milho moído em relação à raspa de mandioca assemelha-se aos resultados obtidos por PILAR et al. (1998), que observaram redução significativa da conversão alimentar da matéria seca com a substituição do milho pelo bagaço de mandioca.

\section{CONCLUSÕES}

A utilização do resíduo de vitivinícolas na alimentação de ovinos em terminação mostrou ser boa alternativa volumosa quando associada a diferentes fontes energéticas. As combinações do resíduo de vitivinícolas com o farelo de palma e com o grão de milho moído apresentaram bons desempenhos, superando a combinação do resíduo de vitivinícolas à raspa de mandioca. A utilização desse resíduo pode trazer benefícios para a composição das dietas de pequenos ruminantes na região do Vale do São Francisco, garantindo maior disponibilidade de alimentos principalmente no período de escassez de forragem.

\section{AGRADECIMENTOS}

Ao Programa de Pós-graduação em Zootecnia da Universidade Federal da Paraíba, pela oportunidade de realização do curso de Mestrado; à Embrapa Semi-Árido, pela concessão de toda a estrutura material e humana necessária para a execução do trabalho e o Conselho Nacional de Desenvolvimento Científico e Tecnológico e à Coordenação de Aperfeiçoamento de Pessoal de Nível Superior, pela colaboração financeira.

\section{REFERÊNCIAS}

ARAúJO, G.G.L. de. et al. Feno de maniçoba: uma alternativa de volumoso para ovinos no Semi-árido brasileiro: consumo, digestibilidade e desempenho animal. Petrolina, PE: Embrapa Semi-Árido, 2001. 11p. (Boletim de Pesquisa e Desenvolvimento, 59).

BARROS, N.N. et al. Terminação de borregos em confinamento no Nordeste do Brasil. Sobral, CE: Embrapa Caprinos, 1997. 24p. (Circular Técnico, 12).

CARVALHO, F.F.R. et al. Uso da casca de café na alimentação de ovinos em crescimento. In: REUNIÃO ANUAL DA SOCIEDADE BRASILEIRA DE ZOOTECNIA, 32., 1995, Brasília. Anais... Brasília: SBZ, 1995. p.181-183.

CUNHA, M.G.G. et al. Utilização do resíduo agroindustrial do abacaxi no desempenho de cordeiros Santa Inês. In: REUNIÃO ANUAL DA SOCIEDADE BRASILEIRA DE ZOOTECNIA, 41., 2004, Campo Grande, MS. Anais... Campo Grande, MS: SBZ, 2004. Seção de Caprinos e Ovinos. CD-ROM.

EUCLIDES FILHO, K. et al. Avaliação dos animais Nelore e seus mestiços com Charolês e Chianina, em três dietas. 1. Ganho de peso e conversão alimentar. Revista Brasileira de Zootecnia, v.26, n.1, p.66-72, 1996.

MENDES NETO, J. et al. Uso da cana-de-açúcar na terminação de ovinos. In: REUNIÃO ANUAL DA SOCIEDADE BRASILEIRA DE ZOOTECNIA, 35., 1998, Botucatu-SP. Anais... Botucatu: SBZ, 1998. V.1, p.461-463.

MERTENS, D.R. Regulation of forage intake. In: FAHEY J.R., G.C. (Ed). Forage quality, evaluation and utilization. Madison: American Society of Agronomy, 1994. p.450-493.

NATIONAL RESEARCH COUNCIL - NRC. Nutrient requirements of sheep. Washington, DC, 1975. 76p.

NEUMANN, A.L. Beef catlle. Urbana: University of Illinois, 1977. 883p.

OLIVEIRA, E.R. de. Aproveitamento de resíduos agroindustriais na alimentação de ovinos. In: SIMPÓSIO INTERNACIONAL SOBRE CAPRINOS E OVINOS DE CORTE, 2., 2003, João Pessoa, PB. Anais... João Pessoa: Sincorte, 2003. 672p.

PÉREZ, J.R.O.; GARCIA, I.F.F. Características de carcaça de cordeiros santa inês e bergamácia com diferentes níveis de dejetos de suínos na dieta. In: REUNIÃO ANUAL DA SOCIEDADE BRASILEIRA DE ZOOTECNIA, 35., 1998, Botucatu-SP. Anais... Botucatu: SBZ, 1998. V.1, p.176-178.

PILAR, R.C. et al. Grão de milho (Zea mays), bagaço de maçã (Malus doméstica) e/ou bagaço de mandioca (Manihot esculenta) para alimentação de ovinos. In: REUNIÃO ANUAL DA SOCIEDADE BRASILEIRA DE ZOOTECNIA, 35., 1998, Botucatu-SP. Anais... Botucatu: SBZ, 1998. V.1, p.167-169.

SAS Statistical Analysis System. User's guide. Cary, NC, 2004. 846p.

SILVA, D.J.S.; QUEIROZ, A.C. Análise de alimentos: métodos químicos e biológicos. Viçosa: UFV, 2002. 235p. il.

SIQUEIRA, E.R. Confinamento de ovinos. In: SIMPÓSIO PAULISTA DE OVINOCULTURA E ENCONTRO INTERNACIONAL DE OVINOCULTURA, 5., 1999, Botucatu. Anais... Botucatu: UNESP, CATI, IZ, ASPACO, 1999. p.5259 